\title{
Correlação entre produção de feijão e atributos físicos de um Latossolo em Mato Grosso do Sul
}

\author{
Rafael Montanari', Douglas Martins Pereira Pellin², Carlos Antonio da Silva Júnior \\ Morel de Passos e Carvalho ${ }^{4}$, Máila Terra Gioia ${ }^{5}$, Flávio Carlos Dalchiavon ${ }^{6}$, Antonio Paz González ${ }^{7}$
}

\begin{abstract}
RESUMO
No Brasil, a cultura do feijoeiro é uma das mais representativas explorações agrícolas, não só pela área de cultivo, como também pelo valor econômico de sua produção. No ano agrícola de 2006/07, no município de Selvíria (MS), foi analisada a produtividade de grãos do feijoeiro, em função de alguns atributos físicos de um Latossolo Vermelho distroférrico, em sistema de cultivo mínimo e irrigado com pivô central. Este trabalho objetivou avaliar, dentre os atributos físicos do solo, sob cultivo mínimo, aqueles que melhor expliquem, pela correlação de Pearson e espacialmente, a variabilidade da produtividade de grãos de feijão. Para tanto, foi instalada uma malha geoestatística, para a coleta de dados do solo e da planta, com 117 pontos amostrais, numa área de $2025 \mathrm{~m}^{2}$ e declive homogêneo de $0,055 \mathrm{~m} \mathrm{~m}^{-1}, 5 \%$. Os resultados mostraram que houve baixa produtividade de grãos do feijoeiro, ocorrida provavelmente por causa de uma menor densidade de plantas que esse sistema proporcionou. Dessa forma, para o sistema de cultivo mínimo do solo, a produtividade de feijão pôde ser explicada, em função da porosidade total e da densidade do solo.
\end{abstract}

Palavras-chave: sistema de manejo, resistência à penetração, umidade, densidade do solo, Phaseolus vulgaris L.

\section{ABSTRACT}

\section{Correlation between common bean production and physical attributes of an Oxisol in Mato Grosso do Sul State, Brazil}

In Brazil, common bean is in one of the most representative economic crops, not only because of its growing area but also because of the economic value of its production. In the crop year 2006/07, in Selvíria (MS), we analyzed the common bean yield as a function of some physical attributes of a Typic Acrustox in minimum tillage and center pivot irrigation system. The aim of this work was to evaluate among the soil physical attributes, under minimum tillage, those that better explain the variability of bean yield using the Pearson and spatial correlations,. A geostatistical grid was installed to collect data from soil and plants, with 117 sampling points in an area of $2025 \mathrm{~m}^{2}$ and homogeneous slope of $0.055 \mathrm{~m} \mathrm{~m}^{-1}$. The results showed a low yield of bean, which occurred probably due to a lower density of plants that the system provided. Thus, for the minimum tillage system, the bean yield could be explained as a function of total porosity and bulk density.

Key words: management system, penetration resistance, soil moisture, bulk density, Phaseolus vulgaris L.

Recebido para publicação em 28/12/2011 e aprovado em 14/06/2013.

'Engenheiro-Agrônomo, Doutor. Departamento de Fitossanidade, Engenharia Rural e Solos, Faculdade de Engenharia, Universidade Estadual Paulista "Júlio de Mesquita Filho", Campus de Ilha Solteira, Avenida Brasil, 56, Centro, Caixa Postal 31, 15385-000, Ilha Solteira, São Paulo, Brasil. montanari@agr.feis.unesp.br (autor para correspondência).

${ }^{2}$ Engenheiro-Agrônomo, Mestre. Departamento de Ciências Agrárias, Universidade Federal da Grande Dourados, Rodovia Itahum, Km 12, 79200-000, Dourados, Mato Grosso do Sul, Brasil. douglas.martins@agronomo.eng.br

3Engenheiro-Agrônomo. Departamento de Ciências Agrárias, Universidade Estadual de Maringá, Avenida Colombo, 5790, Maringá, Paraná, Brasil. carlos-junior89@ hotmail.com ${ }^{4}$ Engenheiro-Agrônomo. Departamento de Fitossanidade, Engenharia Rural e Solos, Faculdade de Engenharia, Universidade Estadual Paulista "Júlio de Mesquita Filho", Campus de Ilha Solteira, Avenida Brasil, 56, Centro, Caixa Postal 31, 15385-000, Ilha Solteira, São Paulo, Brasil. morel@agr.feis.unesp.br

${ }^{5}$ Engenheira-Agrônoma, Mestre. Departamento de Fitossanidade, Engenharia Rural e Solos, Universidade Estadual Paulista "Júlio de Mesquita Filho", Campus de Ilha Solteira, Avenida Brasil, 56, Centro, Caixa Postal 31, 15385-000, Ilha Solteira, São Paulo, Brasil. terragioia@ hotmail.com

${ }^{6}$ Engenheiro-Agrônomo, Doutor. Instituto Federal de Mato Grosso, Campus Campo Novo do Parecis, Departamento de Agronomia, Rodovia MT 235, Km 12, Zona Rural, Caixa Postal 100, 78360-000, Campo Novo do Parecis, Mato Grosso, Brasil. flavio.dalchiavon@cnp.ifmt.edu.br

${ }^{7}$ Engenheiro-Agrônomo, Doutor. Universidad de A Coruña, Facultade de Ciencias, A Zapateira, s/n 15071, A Coruña, Espanha. tucho@udc.es 


\section{INTRODUÇÃO}

No Brasil, a cultura do feijoeiro (Phaseolus vulgaris L.) vem passando por profundas mudanças nos últimos anos. Nas décadas de 80/90, caracterizava-se por cultivos, em pequenas áreas, com pouca tecnologia, voltados para a subsistência e apostando na instabilidade do mercado (Dalchiavon et al., 2011). Trata-se o feijão de um alimento bastante consumido pela população mundial, principalmente pelo brasileiro, sendo a sua principal fonte de proteína vegetal. Seu teor proteico pode atingir $33 \%$, com valor energético de 3,41 cal g-1 (Pompeu, 1987).

Na safra 2011/2012, sua produção chegou a 3,5 milhões de toneladas, ocupando uma área de aproximadamente 3,9 milhões de hectares, com produtividade média de $900 \mathrm{~kg} \mathrm{ha}^{-1}$ (Conab, 2011). Ainda, com relação à referida produtividade, a literatura cita os seguintes quantitativos: (a) $1.000-3.000 \mathrm{~kg} \mathrm{ha}^{-1}$, para o feijão irrigado, no Estado de São Paulo (Fahl et al., 1998); e (b) 1.239 e $1.895 \mathrm{~kg}$ ha $^{-1}$, respectivamente, para os Estados de São Paulo e Goiás, assim como a produtividade de $3.000 \mathrm{~kg} \mathrm{ha}^{-1}$, quando empregado adequado nível tecnológico (Montanari et al., 2010).

Existem evidências de que a densidade, a resistência à penetração de raízes e a umidade do solo estão relacionadas com seu estado de compactação, e muitos trabalhos têm buscado os valores desses atributos que indiquem restrições ao crescimento das raízes das plantas e que contribuem para a diminuição da produtividade. A dificuldade, portanto, está em separar os efeitos desses atributos físicos e os da umidade do solo. Em vista disso, persistem dúvidas sobre o atributo que melhor caracterize o estado de compactação e que seja sensível às variações de manejo do solo (Bonini et al., 2011; Campos et al., 2013).

Os sistemas de preparo de solo, utilizados no Brasil, para o estabelecimento da cultura do feijoeiro são o cultivo mínimo (preparo reduzido), o plantio direto e o convencional. Nos dias atuais, o sistema mais utilizado ainda é o convencional, que consiste no revolvimento de camadas superficiais, objetivando incorporar corretivos e fertilizantes, bem como aumentar os espaços porosos e, com isso melhorar a permeabilidade e o armazenamento de água, facilitando o crescimento das raízes das plantas (Montanari et al, 2010).

Com o surgimento da agricultura de precisão, ultimamente, no Brasil, o estudo geoestatístico dos atributos físicos do solo relacionados com a produtividade do feijão vem-se intensificando (Roque et al., 2008; Martins et al., 2009; Campos et al., 2013). Assim, em relação à produtividade de feijão, a densidade de partículas, a densidade do solo, a RP e a umidade gravimétrica, os alcances da dependência espacial observados pelos referidos auto- res variaram entre: (a) 6,1 e 29,8 m, para a produtividade do feijão; (b) efeito pepita puro, para a densidade de partículas; c) 29,9 e 39,8 m, para a densidade do solo; (d) 2,2 e 67,1 m, para a RP; e (e) 11,8 e 65,8 m, para a umidade gravimétrica. Por outro lado, Montanari et al. (2010) observaram significativa co-krigagem entre a produtividade de feijão e a densidade da partícula do solo, com coeficiente de determinação espacial $\left(\mathrm{r}^{2}\right)$ de 0,635 .

Diante do exposto, este trabalho objetivou avaliar, entre os atributos físicos estudados do solo sob cultivo mínimo, aqueles que melhor expliquem, linear e espacialmente, a variabilidade da produtividade de grãos de feijão.

\section{MATERIAL E MÉTODOS}

O trabalho foi realizado no ano agrícola 2006/2007, na Fazenda de Ensino, Pesquisa e Extensão, da Faculdade de Engenharia de Ilha Solteira - UNESP, localizada no município de Selvíria (MS), em latitude de $20^{\circ} 22^{\prime}$ S e longitude de $51^{\circ} 22^{\prime} \mathrm{W}$, com precipitação média anual de 1300 mm e temperatura média de $23,7^{\circ} \mathrm{C}$. O tipo climático é Aw, segundo a classificação de Kçppen-Geiger, caracterizado como tropical úmido, com estação chuvosa, no verão, e seca, no inverno (Demattê, 1980).

O solo no qual a malha experimental foi instalada, irrigado por um sistema de pivô central, foi classificado conforme Embrapa (2006), como um Latossolo Vermelho distroférrico típico, A moderado, hipodistrófico, álico, caulinítico, férrico, muito profundo, moderadamente ácido (Typic Acrustox), com declividade homogênea de 0,055 $\mathrm{m} \mathrm{m}^{-1}$. A granulometria foi analisada desde a camada superficial até $0,30 \mathrm{~m}$, apresentando $620 \mathrm{~g} \mathrm{~kg}^{-1}$ de argila, 100 $\mathrm{g} \mathrm{kg}^{-1}$ de silte e $280 \mathrm{~g} \mathrm{~kg}^{-1}$ de areia, conferindo-lhe a textura muito argilosa. O solo estudado vem, há pelo menos vinte anos, sendo cultivado com a sucessão de culturas milho/ feijão, respectivamente, semeadas no verão e inverno. Nos anos de 1998 e 2003, para os dois casos, o solo foi preparado com o arado de aivecas.

Especificamente, antes da semeadura deste experimento, ocorrida em 5/5/2006, a área experimental foi cultivada com milho e, após a colheita, dessecada com a aplicação de $1,8 \mathrm{~kg} \mathrm{ha}^{-1}$ do ingrediente ativo do herbicida glifosato. Foi utilizado o cultivo mínimo, que constou de apenas uma escarificação a, aproximadamente, 0,30 m de profundidade, seguindo-se a semeadura, com o cultivar Pérola, no espaçamento de $0,45 \mathrm{~m}$ entrelinhas, com a densidade de 300.000 plantas por hectare. Para tanto, empregaramse, em média, 14 sementes por metro de semeadura. As práticas normais de condução da cultura, como o tratamento fitossanitário e o cultivo químico, foram executadas, homogeneamente, em toda a área experimental, conforme recomendações de Fahl et al. (1998). 
Foram definidas as direções $x$ e $y$ do sistema de coordenadas cartesianas, num lançante estabelecido entre dois terraços agrícolas. Empregou-se o nível ótico comum, efetuando-se o estaqueamento global da malha experimental, dentro do mencionado lançante, em junho de 2006. A malha foi constituída de nove transeções, com $40 \mathrm{~m}$ de comprimento, em ambas as direções dos eixos, perfazendo uma área de $2.025 \mathrm{~m}^{2}$. As transeções foram espaçadas de 5,00 m, com pontos amostrais na forma de 5,00 x 5,00 m, contendo 81 deles. No entanto, também foram alocados, dentro da grande malha, pontos com espaçamentos menores do que os mencionados, com 1,67 m entre eles, visando a detalhar o estudo da dependência espacial. Como, neste caso, foram 36, o total de pontos amostrais da malha foi de 117. Todos os atributos pesquisados, do solo e da planta, foram individualmente coletados no entorno e o mais próximo do ponto amostral da malha experimental, sendo o feijão colhido no estádio fenológico entre R7 e R8.

A colheita da cultura de feijão consistiu no arranquio das plantas e o acondicionamento do material em sacos de polietileno, previamente identificados, efetuada aos 100 dias após a semeadura. A seguir, o material proveniente de cada ponto amostral foi colocado para secar num terreiro sob o sol. Posteriormente, a trilha e debulha foram efetuadas com o pisoteio por rodado de trator, sobre todos os sacos, devidamente amontoados em um terreiro (trilha no terreiro). Em seguida, foram peneirados, de forma a se obter, separadamente, a palhada da planta e os grãos do feijão. Os atributos avaliados da cultura do feijoeiro foram: produtividade de grãos (PRG), com os valores transformados para as condições padronizadas de $0,13 \mathrm{~kg} \mathrm{~kg}^{-1}$ de umidade, representados em kg ha-1, número de vagens por planta (NVP), número de grãos por vagem (NGV), número de grãos por planta (NGP), e massa de cem grãos (MCG), em gramas. Foram coletadas todas as plantas do entorno do ponto amostral estaqueado. A área representativa dessa coleta foi de $3,20 \mathrm{~m}^{2}$, com quatro linhas de plantas $(1,80 \mathrm{~m} \mathrm{x} \mathrm{1,80} \mathrm{m).} \mathrm{Para} \mathrm{análise} \mathrm{dos}$ atributos físicos do solo, foram determinados a densidade do solo $\left(\mathrm{D}_{\mathrm{S}}\right)$, a densidade da partícula $\left(\mathrm{D}_{\mathrm{P}}\right)$, a porosidade total (PT), a resistência à penetração (RP), a umidade gravimétrica (U) e a umidade volumétrica $(\theta)$, em amostras coletadas em junho de 2006, em três profundidades: 0,000,10 m, 0,10-0,20 m e 0,20-0,30 m.

A densidade do solo foi determinada pelo método do anel volumétrico, enquanto a umidade gravimétrica (Equação 1) foi determinada pelo método termogravimétrico, utilizando-se balança analítica com precisão de $\pm 0,005 \mathrm{~g}$ (Kiehl, 1979), e, a densidade da partícula, pelo método do balão volumétrico (com uso de álcool) (Embrapa, 1997). Dessa forma, a porosidade total do solo (PT) foi calculada conforme a Equação 2 (Libardi, 2005).
$\mathrm{UV}=\mathrm{UG} \times \mathrm{DS}$

$\mathrm{PT}=\left(1-\frac{\mathrm{DS}}{\mathrm{DP}}\right) \times 100$

em que: UV é a umidade volumétrica $\left(\mathrm{m}^{3} \mathrm{~m}^{-3}\right)$, U é a umidade gravimétrica $\left(\mathrm{kg} \mathrm{kg}^{-1}\right), \mathrm{D}_{\mathrm{S}}$ é a densidade do solo $(\mathrm{kg}$ $\left.\mathrm{dm}^{-3}\right)$, e $\mathrm{D}_{\mathrm{P}}$ é a densidade de partícula $\left(\mathrm{kg} \mathrm{dm}^{-3}\right)$. Para a UG foram utilizadas amostras de solo com estrutura deformada, coletadas com uma sonda caladora.

Os dados da resistência à penetração foram obtidos por meio de um penetrômetro (Planalsucar) e os resultados, obtidos em impactos $\mathrm{dm}^{-1}$, foram convertidos para resistência do solo à penetração, pela Equação 3 (Stolf, 1991):

$\operatorname{RP}\left(\mathrm{kgf} \mathrm{cm}^{-2}\right)=5,6+6,89 \mathrm{~N}\left(\right.$ impactos $\left.\mathrm{dm}^{-1}\right)$.

Utilizando-se a fórmula descrita para conversão da RP, de $\mathrm{kgf} \mathrm{cm}^{-2}$ para MPa, multiplicou-se o resultado obtido por 0,098 .

Para cada atributo estudado, efetuou-se a análise descritiva clássica, com auxílio do software estatístico SAS (Sas Institute, 1999), com que foram calculados a média, a mediana, os valores mínimos e máximos, o desvio padrão, o coeficiente de variação, a curtose, a assimetria e a distribuição de frequência. Posteriormente, realizou-se a identificação dos outliers, efetuando-se a substituição dos seus valores pelo valor médio dos circunvizinhos contidos na malha.

Para testar a hipótese de normalidade, ou de lognormalidade, foi utilizada a estatística de Shapiro \& Wilk, a 5\%. Também, foi montada a matriz de correlação, objetivando efetuar as correlações lineares simples para as combinações, duas a duas, entre todos os atributos estudados, assim como apresentar as análises de regressões para os pares de maior interesse. Isoladamente para cada atributo, foi analisada sua dependência espacial, pelo cálculo do semivariograma simples, pelo uso do pacote Gamma Design Software (GS+, 2004).

Os ajustes dos semivariogramas, em função de seus modelos, foram efetuados prioritariamente pela seleção inicial dos seguintes parâmetros: (a) menor soma dos quadrados dos desvios (RSS); (b) maior coeficiente de determinação $\left(\mathrm{r}^{2}\right)$; e (c) maior avaliador da dependência espacial (ADE). A decisão final do modelo que representou o ajuste foi realizada pela validação cruzada, assim como para a definição do tamanho da vizinhança que proporcionou a melhor malha de krigagem, realizada por meio da krigagem em blocos. Para cada atributo, foram relacionados o efeito pepita $\left(\mathrm{C}_{\mathrm{o}}\right)$, o alcance $\left(\mathrm{A}_{\mathrm{o}}\right)$ e o patamar $\left(\mathrm{C}_{\mathrm{o}}+\right.$ C). A análise do avaliador da dependência espacial (ADE) foi feita conforme a Equação 4 (GS $\left.{ }^{+}, 2004\right)$ :

$\mathrm{ADE}=[\mathrm{C} /(\mathrm{C}+\mathrm{Co})] \times 100$ 
sendo que o ADE é o avaliador da dependência espacial; $\mathrm{C}$, a variância estrutural; e C $+\mathrm{C}_{\mathrm{o}}$, o patamar. A interpretação proposta para o ADE foi a seguinte: $\mathrm{ADE} \leq 25 \%$ indicou variável espacial fracamente dependente; $25 \%<$ $\mathrm{ADE} \leq 75 \%$ indicou variável espacial moderadamente dependente; e ADE > $75 \%$ indicou variável espacial fortemente dependente. Por outro lado, sabe-se que a validação cruzada é uma ferramenta destinada a avaliar modelos alternativos de semivariogramas simples e cruzados, que efetuarão a krigagem, respectivamente. Na análise, cada ponto contido dentro do domínio espacial, é removido, individualmente, sendo seu valor estimado como se não existisse. Dessa forma, pode-se construir um gráfico de valores estimados, versus observados, para todos os pontos. O coeficiente de correlação (r) entre esses valores reflete a eficiência do ajuste, dada pela técnica da soma dos quadrados dos desvios, representando a equação de regressão linear em questão.

Um ajuste perfeito teria o coeficiente de regressão igual a 1 e a linha do melhor ajuste coincidiria com o modelo perfeito, isto é, com o coeficiente linear igual a zero e o angular igual a 1 (GS $\left.{ }^{+}, 2004\right)$. Assim, trabalhando-se na obtenção do número ideal de vizinhos, foram obtidos, por meio da interpolação, os mapas de krigagem, para análise da dependência e da interdependência espacial entre os atributos. Os componentes geoestatísticos determinados foram o semivariogramas simples, a validação cruzada e a krigagem.

\section{RESULTADOS E DISCUSSÃO}

Na Tabela 1, está apresentada a análise descritiva dos atributos estudados. De acordo com Pimentel-Gomes e Garcia (2002), a variabilidade de um atributo pode ser classificada segundo a magnitude de seu coeficiente de variação (CV). Suas classes foram determinadas como baixa $(\mathrm{CV} \leq 10 \%)$, média $(10 \%<\mathrm{CV} \leq 20 \%)$, alta $(20 \%<\mathrm{CV} \leq$ $30 \%)$ e muito alta $(\mathrm{CV}>30 \%)$. Portanto, a produtividade de grãos do feijão (PRG) e o número de grãos por vagem (NGV) apresentaram média variabilidade, com coeficientes de variação de 18,3 e 12,4\%, respectivamente. Assim, neste aspecto, foi similar aos obtidos por Freddi et al. (2005), estudando um Latossolo Vermelho distroférrico, sob preparo convencional, e Megda et al. (2008), avaliando um Latossolo Vermelho distroférrico, sob plantio direto, que também encontraram valores de média variabilidade (17, 17 e 19\%). Já Martins et al. (2009), quando analisaram um Latossolo Vermelho distroférrico, sob plantio direto, em malhas regulares de 135 pontos amostrais, encontraram alta variabilidade $(24 \%)$ para a produtividade de grãos do feijão. Já o número de vagens por planta (NVP) e o número de grãos por planta (NGP) apresentaram alta variabilidade, com coeficientes de variação de
20,6 e $24,2 \%$, respectivamente, enquanto a massa de cem grãos (MCG) teve baixa variabilidade $(4,4 \%)$. As taxas de variabilidade, de média a alta, encontradas para a maioria dos componentes de produção do feijão, com exceção da MCG, podem ser explicadas, possivelmente, pelo fato de o preparo do solo (cultivo mínimo) introduzir ao solo heterogeneidade, incrementando, assim, o valor do coeficiente de variação dos atributos da cultura de feijão. Freddi et al. (2005), estudando a produtividade de feijão num Latossolo de Cerrado, encontraram também alta variabilidade no sistema convencional de preparo do solo para o referido atributo.

As taxas de variabilidade da densidade do solo $\left(D_{S}\right)$ e da densidade da partícula $\left(\mathrm{D}_{\mathrm{P}}\right)$, nas três camadas de solo estudadas, foram baixas (Tabela 1), com coeficientes de variação entre 4 e10\%. Assim, os dados das densidades, do solo e da partícula, assemelham-se com aqueles obtidos por Montanari et al. (2010), os quais variaram entre 4 e $8 \%$, quando trabalharam com um Latossolo Vermelho distroférrico sob plantio direto. As baixas variabilidades para as densidades do solo e da partícula verificam-se por causa da baixa variação dos valores dos respectivos atributos, pois a densidade do solo é atribuída ao manejo realizado, que no caso, foi o cultivo mínimo, sistema em que a parte do solo mobilizada é apenas a linha de semeadura na profundidade de 0,00-0,05 m, deixando-se o restante da área sem manejo, provocando, assim, uma homogeneidade do referido atributo, que, ademais, foi amostrado na entrelinha de semeadura. Já a densidade da partícula do solo, atributo referente aos minerais presentes, cujo principal representante é a caulinita, apresenta densidade de partícula de $2,65 \mathrm{~kg} \mathrm{dm}^{-3}$, muito próximos do qual estão os valores encontrados neste estudo.

A umidade gravimétrica $(\mathrm{U})$ e a umidade volumétrica $(\theta)$ apresentaram variabilidade de baixa a média (Tabela 1), com coeficientes de variação entre 8 e $15 \%$. Esses dados concordam com aqueles de Carvalho et al. (2002), em um Latossolo Vermelho distrófico, sob preparo convencional, e os de Montanari et al. (2010), estudando um Latossolo Vermelho distroférrico, sob plantio direto para feijão e soja, respectivamente, que variaram entre 5 e $14 \%$.

A porosidade total (PT) apresentou-se com média variabilidade, em ambos os casos (Tabela 1), sendo de 13, 13 , e $12 \%$, respectivamente, para as profundidades de 0 0,10; 0,10-0,20 e 0,20-0,30 m. Esses dados concordaram, para as camadas de 0,00-0,10 e 0,10-0,20 m, com aquele de Souza et al. (2004), de 17\%, obtido num Latossolo Vermelho eutroférrico, em uma malha regular, espaçada de $10 \mathrm{~m}$, com dimensão de 100 x 100 m, sob cultivo de cana-deaçúcar por mais de 30 anos. Contudo, divergem dos de Secco et al. (2005) e Megda et al. (2008), os quais foram baixos, com valores de 4\%, para um Latossolo Vermelho distrófico, e de 4 a $6 \%$, para um Latossolo Vermelho 
distroférrico, em uma malha de amostragem constituída de 75 pontos.

Em relação à resistência à penetração $(\mathrm{RP})$, os valores apresentaram variabilidade muito alta, com coeficientes de variação entre 35 e 58\% (Tabela 1). Assim, esses dados de resistência à penetração concordaram com aquele de Souza et al. (2006), que foi de $37 \%$, para as profundidades de $0,00-0,15 ; 0,15-0,30$ e 0,30-0,45 m, em um Latossolo Vermelho distrófico.

Em relação à distribuição de frequência dos atributos, a produtividade de grãos (PRG), o número de grãos por planta (NGP) e a massa de cem grãos (MCG) apresentaram distribuição de frequência do tipo normal, com coeficientes de assimetria positiva de 0,458 para PRG, e negativa, iguais a -0,319 e -0,086, respectivamente, para NGP e MCG (Tabela 1). Já os coeficientes de curtose positiva para PRG, NGP e MCG foram de 0,334; 0,787; 0,679, respectivamente. Contudo, e independentemente desses coeficien- tes, esses atributos não foram significativos, a 5\% de probabilidade, pelo teste de normalidade de Shapiro \& Wilk, uma vez que, suas respectivas probabilidades foram de 0,065; 0,233 e 0,197, ou seja, de distribuição normal. Porém, os valores de vagens por planta (NVP) e número de grãos por vagem (NGV) apresentaram distribuição de frequência do tipo lognormal e indeterminado, respectivamente (Tabela 1). Resultados semelhantes para a PRG, com distribuição de frequência do tipo normal, também foram encontrados por Freddi et al. (2005), Megda et al. (2008), Martins et al. (2009) e Montanari et al. (2010).

Os atributos do solo DS1, DS3, DP1, DP2, DP3, PT1, PT3, UG1, UG2, UV1, UV2 e UV3 apresentaram distribuição de frequência do tipo normal, portanto, as respectivas medidas de tendência central deverão ser representadas pelos valores médios, com coeficientes de assimetria positiva entre 0,039 e 0,500 , assim como negativa entre $-0,499$ e -0,070. Já os coeficientes de curtose

Tabela 1. Análise descritiva inicial de alguns atributos da cultura do feijão e de um Latossolo Vermelho distroférrico sob cultivo mínimo em Selvíria (MS)

\begin{tabular}{|c|c|c|c|c|c|c|c|c|c|c|}
\hline \multirow{3}{*}{ Atributo $^{(a)}$} & \multicolumn{10}{|c|}{ Medidas estatísticas descritivas } \\
\hline & \multirow[t]{2}{*}{ Média } & \multirow[t]{2}{*}{ Mediana } & \multirow[b]{2}{*}{ Mínimo } & \multirow[b]{2}{*}{ Máximo } & \multirow{2}{*}{$\begin{array}{l}\text { Desvio } \\
\text { Padrão }\end{array}$} & \multirow[b]{2}{*}{$\mathrm{CV}(\%)$} & \multirow[b]{2}{*}{ Curtose } & \multirow[b]{2}{*}{ Assimetria } & \multicolumn{2}{|c|}{$\begin{array}{c}\text { Probabilidade } \\
\text { do teste } \\
\text { (b) }\end{array}$} \\
\hline & & & & & & & & & $\operatorname{Pr}<w$ & DF \\
\hline \multicolumn{11}{|c|}{ Atributos da planta } \\
\hline PRG $\left(\mathrm{kg} \mathrm{ha}^{-1}\right)$ & 2034,8 & 2018,8 & 1214,9 & 3152,2 & 372,4 & 18,3 & 0,334 & 0,458 & 0,065 & NO \\
\hline NVP & 10,2 & 10,0 & 6,0 & 16,0 & 2,113 & 20,6 & $-0,005$ & $-0,308$ & 0,354 & $\mathrm{LN}$ \\
\hline NGV & 5,8 & 6,0 & 5,0 & 7,0 & 0,735 & 12,4 & - & - & - & IN \\
\hline NGP & 49,5 & 50,0 & 5,0 & 75,0 & 11,998 & 24,2 & 0,787 & $-0,319$ & 0,233 & NO \\
\hline $\operatorname{MCG}(\mathrm{g})$ & 23,3 & 23,4 & 19,8 & 25,7 & $1,035,0$ & 4,4 & 0,679 & $-0,086$ & 0,197 & NO \\
\hline \multicolumn{11}{|c|}{ Atributos físicos do solo } \\
\hline $\mathrm{DS} 1\left(\mathrm{~kg} \mathrm{dm}^{-3}\right)$ & 1,261 & 1,246 & 0,921 & 1,574 & 0,127 & 10,1 & $-0,072$ & 0,119 & 0,823 & $\mathrm{NO}$ \\
\hline $\operatorname{DS} 2\left(\mathrm{~kg} \mathrm{dm}^{-3}\right)$ & 1,311 & 1,335 & 0,997 & 1,507 & 0,116 & 8,8 & - & - & - & IN \\
\hline DS3 $\left(\mathrm{kg} \mathrm{dm}^{-3}\right)$ & 1,357 & 1,366 & 1,170 & 1,570 & 0,074 & 5,5 & 0,301 & $-0,216$ & 0,121 & NO \\
\hline $\mathrm{DP} 1\left(\mathrm{~kg} \mathrm{dm}^{-3}\right)$ & 2,235 & 2,226 & 1,788 & 2,550 & 0,121 & 5,5 & 0,788 & $-0,125$ & 0,369 & $\mathrm{NO}$ \\
\hline DP2 $\left(\mathrm{kg} \mathrm{dm}^{-3}\right)$ & 2,190 & 2,183 & 2,004 & 2,446 & 0,100 & 4,6 & $-0,477$ & 0,346 & 0,071 & NO \\
\hline DP3 $\left(\mathrm{kg} \mathrm{dm}^{-3}\right)$ & 2,205 & 2,198 & 1,913 & 2,537 & 0,110 & 5,0 & 0,765 & 0,500 & 0,052 & NO \\
\hline PT1 $\left(\mathrm{m}^{3} \mathrm{~m}^{-3}\right)$ & 0,434 & 0,435 & 0,264 & 0,544 & 0,056 & 12,9 & 0,132 & $-0,499$ & 0,126 & $\mathrm{NO}$ \\
\hline PT2 $\left(\mathrm{m}^{3} \mathrm{~m}^{-3}\right)$ & 0,400 & 0,395 & 0,290 & 0,541 & 0,052 & 13,2 & 0,016 & 0,103 & 0,510 & $\mathrm{LN}$ \\
\hline PT3 $\left(\mathrm{m}^{3} \mathrm{~m}^{-3}\right)$ & 0,382 & 0,377 & 0,242 & 0,479 & 0,044 & 11,5 & 0,516 & $-0,124$ & 0,232 & NO \\
\hline RP1 (MPa) & 1,096 & 0,916 & 0,547 & 2,981 & 0,637 & 58,1 & - & - & - & IN \\
\hline RP2 (MPa) & 2,115 & 2,170 & 0,547 & 4,362 & 1,085 & 51,3 & - & - & - & IN \\
\hline RP3 (MPa) & 2,743 & 2,801 & 0,547 & 5,054 & 0,964 & 35,1 & 0,126 & $-0,317$ & 0,022 & $\mathrm{TN}$ \\
\hline UG1 $\left(\mathrm{kg} \mathrm{kg}^{-1}\right)$ & 0,207 & 0,206 & 0,153 & 0,277 & 0,022 & 10,6 & 0,381 & 0,388 & 0,304 & NO \\
\hline $\mathrm{UG} 2\left(\mathrm{~kg} \mathrm{~kg}^{-1}\right)$ & 0,220 & 0,221 & 0,158 & 0,301 & 0,022 & 10,1 & 0,829 & 0,119 & 0,216 & NO \\
\hline $\mathrm{UG} 3\left(\mathrm{~kg} \mathrm{~kg}^{-1}\right)$ & 0,231 & 0,234 & 0,185 & 0,286 & 0,018 & 8,1 & - & - & - & IN \\
\hline $\mathrm{UV} 1\left(\mathrm{~m}^{3} \mathrm{~m}^{-3}\right)$ & 0,262 & 0,259 & 0,170 & 0,362 & 0,040 & 15,4 & 0,192 & 0,339 & 0,067 & NO \\
\hline $\operatorname{UV} 2\left(\mathrm{~m}^{3} \mathrm{~m}^{-3}\right)$ & 0,289 & 0,296 & 0,200 & 0,383 & 0,039 & 13,8 & $-0,446$ & 0,039 & 0,255 & NO \\
\hline $\operatorname{UV} 3\left(\mathrm{~m}^{3} \mathrm{~m}^{-3}\right)$ & 0,314 & 0,316 & 0,247 & 0,378 & 0,027 & 8,9 & $-0,399$ & $-0,137$ & 0,598 & NO \\
\hline
\end{tabular}

(a) PRG = produtividade de grãos do feijão; NVP = número de vagens por planta; NGV = número de grãos por vagem; NGP = número de grãos por planta; MCG = massa de cem grãos; DS, DP, PT, RP, UG, UV, de 1 a 3, são respectivamente a densidade do solo, densidade da partícula, porosidade total, resistência à penetração, umidade gravimétrica, umidade volumétrica, coletados nas camadas do solo; (b) $\mathrm{DF}=$ distribuição de frequência, sendo NO, LN, TN e IN respectivamente do tipo normal, log-normal, tendendo a normal e indeterminada. 
positiva ficaram entre 0,106 e 0,829 , assim como as negativas, entre - 0,477 e $-0,072$, sendo que todos esses coeficientes foram não significativos, a $5 \%$ de probabilidade, pelo teste de normalidade de Shapiro \& Wilk, uma vez que, a respectiva probabilidade variou entre 0,052 e 0,823 (Tabela 1).

Dessa forma, as distribuições de frequência do tipo normal, obtida para esses atributos estudados nesta pesquisa, ficaram de acordo com os seguintes autores, classificados conforme o atributo: DS1 e DS3 (Carvalho et al., 2003); DP1, DP2 e DP3 (Santos et al., 2006); PT1 e PT3 (Megda et al., 2008); UG1 e UG2 (Montanari et al., 2010) e UV1, UV2 e UV3 (Martins, 2006). O atributo PT2 apresentou distribuição de frequência do tipo log-normal (Tabela 1), discordando dos resultados encontrados por Megda et al. (2008), que apresentaram em seus estudos distribuição de frequência do tipo normal para a porosidade, na profundidade de $0,10-0,20 \mathrm{~m}$. A não normalidade para a porosidade do solo na camada subsuperficial é atribuída à profundidade da realização da escarificação (cultivo mínimo), que tende a heterogeneizar o terreno.

Em relação à RP3, a distribuição de frequência apresentada foi a do tipo tendendo a normal (Tabela 1). Esses resultados para RP3 discordam do de Carvalho et al. (2006), que encontraram distribuição de frequência do tipo normal, para a profundidade de 0,20-0,30 m, em um Latossolo Vermelho distroférrico, sob plantio direto, numa malha de 119 pontos amostrais.

A distribuição de frequência dos atributos DS2, RP1, RP2 e UG3 foi indeterminada (Tabela 1). Esses resultados discordam do de Santos et al. (2006), que encontraram distribuição de frequência do tipo normal para DS2; do de Carvalho et al. (2002), que verificaram distribuição de frequência dos tipos log-normal e normal, para RP1 e RP2, respectivamente, e do de Santos et al. (2005), cuja distribuição de frequência encontrada, para UG3, foi à do tipo normal.

O valor médio da PRG foi de $2035 \mathrm{~kg} \mathrm{ha}^{-1}$ (Tabela 1), ficando perto daquele de Santos et al. (2005), que foi de $2208 \mathrm{~kg} \mathrm{ha}^{-1}$. Assim, neste trabalho, ele ficou $226 \%$ acima da produtividade média mundial de feijão, que foi de 900 kg ha-1 ${ }^{-1}$, segundo Conab (2011), considerado baixo por ter, a cultura, potencial para produtividade superior a $3500 \mathrm{~kg}$ ha $^{-1}$. Porém, em regiões em que a agricultura é mais tecnificada, como o Estado de São Paulo, a produtividade média já ultrapassa $1200 \mathrm{~kg} \mathrm{ha}^{-1}$ (Camargo et al., 2001).

Os atributos componentes de produção, dados pelo número de vagens por planta (NVP), pelo número de grãos por vagem (NGV), pelo número de grãos por planta (NGP) e pela massa de cem grãos (MCG) apresentaram os seguintes valores médios: $\operatorname{NVP}(10,2), \operatorname{NGV}(5,8), \operatorname{NGP}(49,5)$ e MCG (23,3 g). Esses resultados corroboram os de Silva et al. (2008), que, estudando um Latossolo Vermelho sob cultivo mínimo, encontraram valores médios de NVP $(10,2)$, NGV (4,0), NGP (44,0) e MCG (23,07 g). Os valores médios da DS (DS1 de 1,261 kg dm ${ }^{-3}$, DS2 de $1,311 \mathrm{~kg} \mathrm{dm}^{-3}$ e DS3 de $1,357 \mathrm{~kg} \mathrm{dm}^{-3}$ ), PT (PT1 de 0,434 $\mathrm{m}^{3} \mathrm{~m}^{-3}$, PT2 de $0,400 \mathrm{~m}^{3}$ $\mathrm{m}^{-3}$ e PT3 de 0,382 $\mathrm{m}^{3} \mathrm{~m}^{-3}$ ), RP (RP1 de 1,096 MPa, RP2 de 2,115 MPa e RP3 de 2,743 MPa) foram distintos, em ambas as profundidades (Tabela 1), ocorrendo um aumento das DS's e RP's e diminuição das PT's, conforme o aumento da profundidade, corroborando os dados obtidos por Gabriel Filho et al. (2000), que, estudando um Nitossolo, sob cultivo mínimo, 240 dias após o plantio de mandioca, encontraram valores da DS (DS1 de 1,21 kg dm ${ }^{-3}$, DS2 de $1,17 \mathrm{~kg} \mathrm{dm}^{-3}$ e DS3 de $1,21 \mathrm{~kg} \mathrm{dm}^{-3}$ ) e RP (RP1 de 0,450 $\mathrm{MPa}, \mathrm{RP} 2$ de 1,602 MPa e RP3 de 2,704 MPa). Eles também indicaram que as camadas estudadas encontravam-se compactadas, tornando-se um fator limitante para máxima expressão da produtividade do feijão, prejudicada tanto pelo deficiente crescimento radicular, assim como pelas consequentes deficiências proporcionadas à absorção nutricional. Isso porque seus valores ficaram aquém daqueles do solo considerado ideal, do ponto de vista agronômico, com $0,50 \mathrm{~m}^{3} \mathrm{~m}^{-3}$ de porosidade total, conforme preceitos de Kiehl (1979). Roque et al. (2011), estudando um Latossolo, sob cultivo de cana-de-açúcar, encontraram valores de DS na entrelinha de plantio da cultura de $1,13 \mathrm{~kg} \mathrm{dm}^{-3} \mathrm{e}$, para a linha de plantio, valores de $1,07 \mathrm{~kg}$ $\mathrm{dm}^{-3}$, sugerindo que este solo não se encontrava compactado, diferentemente do encontrado no trabalho anteriormente citado.

A umidade gravimétrica (Tabela 1) apresentou valores de $0,207 \mathrm{~kg} \mathrm{~kg}^{-1}$ (UG1), de 0,220 $\mathrm{kg} \mathrm{kg}^{-1}$ (UG2) e de $0,231 \mathrm{~kg}$ $\mathrm{kg}^{-1}$ (UG3), corroborando os resultados obtidos por Carvalho et al. (2002) e Freddi et al. (2005), que apresentaram aumento desses valores com a profundidade do solo. Por outro lado, ficou diretamente relacionada com o aumento das UVs, as quais foram de $0,262 \mathrm{~m}^{3} \mathrm{~m}^{-3}$ (UV1), de $0,289 \mathrm{~m}^{3}$ $\mathrm{m}^{-3}$ (UV2) e de $0,314 \mathrm{~m}^{3} \mathrm{~m}^{-3}$ (UV3).

Na Tabela 2, estão apresentadas as matrizes de correlação linear simples entre os atributos do feijão (PRG, NVP, NGV, NGP e MCG) e do solo (DS, DP, PT, RP, UG e UV), para o cultivo mínimo. As correlações entre os atributos da planta (Tabela 2) foram significativas para os pares PRG x NVP $\left(\mathrm{r}=0,271^{* *}\right), \operatorname{PRG} \times \mathrm{NGP}\left(\mathrm{r}=0,429^{* *}\right)$, $\operatorname{NGV} x \operatorname{NVP}\left(r=0,741^{* *}\right), \operatorname{NGP} \times \operatorname{NVP}\left(r=0,654^{* *}\right)$ e NGP x $\operatorname{NGV}\left(r=0,478^{* *}\right)$. A correlação entre a PRG e os atributos do solo (Tabela 2) apresentou significância exclusivamente para os pares: 1) PRG x DS1 $\left.\left(\mathrm{r}=-0,187^{*}\right), 2\right) \mathrm{PRG} \mathrm{x}$ PT1 $\left(r=0,200^{*}\right)$ e 3) PRG x UV1 $\left(r=-0,198^{*}\right)$. O único par que apresentou correlação positiva foi o PRG x PT1, indicando que, com o aumento da porosidade total (PT1,) na camada de 0,00-0,10 m, ocorrerá o mesmo com a PRG. Por outro lado, a DS1 e UV1 apresentaram correlação negativa com a PRG. 


\begin{tabular}{|c|c|c|c|c|c|c|c|c|c|c|c|c|c|c|c|c|c|}
\hline \multirow[b]{2}{*}{ Atributos $^{(a)}$} & \multicolumn{17}{|c|}{ Coeficiente de correlação ${ }^{(b)}$} \\
\hline & PRG & NVP & NGV & NGP & MCG & DS1 & DS2 & DS3 & DP1 & DP2 & DP3 & PT1 & PT2 & PT3 & RP1 & RP2 & RP3 \\
\hline NVP & $0,271^{* *}$ & - & - & - & - & - & - & - & - & - & - & - & - & - & - & - & - \\
\hline NGV & 0,111 & $0,741^{* *}$ & - & - & - & - & - & - & - & - & - & - & - & - & - & - & - \\
\hline NGP & $0,429^{* *}$ & $0,654^{* *}$ & $0,478^{* *}$ & - & - & - & - & - & - & - & - & - & - & - & - & - & - \\
\hline MCG & $-0,017$ & $-0,057$ & $-0,057$ & 0,024 & - & - & - & - & - & - & - & - & - & - & - & - & - \\
\hline DS1 & $-0,187^{*}$ & 0,069 & 0,128 & $-0,071$ & 0,144 & - & - & - & - & - & - & - & - & - & - & - & - \\
\hline DS2 & $-0,072$ & 0,112 & 0,064 & $-0,018$ & 0,065 & $0,434^{* *}$ & - & - & - & - & - & - & - & - & - & - & - \\
\hline DS3 & 0,009 & $-0,006$ & $-0,051$ & $-0,092$ & $-0,011$ & 0,060 & $0,223^{*}$ & - & - & - & - & - & - & - & - & - & - \\
\hline DP1 & 0,015 & $-0,076$ & $-0,004$ & $-0,084$ & 0,025 & $0,244^{* *}$ & 0,116 & 0,073 & - & - & - & - & - & - & - & - & - \\
\hline DP2 & 0,090 & $-0,027$ & $-0,044$ & 0,009 & $-0,112$ & 0,038 & $0,203^{*}$ & 0,158 & 0,108 & - & - & - & - & - & - & - & - \\
\hline DP3 & 0,157 & 0,035 & 0,121 & $-0,060$ & 0,039 & 0,009 & $-0,047$ & $-0,006$ & 0,014 & 0,134 & - & - & - & - & - & - & - \\
\hline PT1 & $0,200^{*}$ & $-0,093$ & $-0,075$ & 0,032 & $-0,153$ & $-0,785^{* *}$ & $-0,278^{* *}$ & $-0,089$ & $0,227^{*}$ & 0,020 & 0,008 & - & - & - & - & - & - \\
\hline PT2 & 0,130 & $-0,113$ & $-0,044$ & 0,020 & $-0,126$ & $-0,329^{* *}$ & $-0,749^{* *}$ & $-0,102$ & $-0,027$ & $0,275^{* *}$ & 0,157 & $0,339^{* *}$ & - & - & - & - & - \\
\hline PT3 & 0,179 & 0,090 & 0,165 & 0,083 & $-0,041$ & $-0,095$ & $-0,167$ & $-0,664^{* *}$ & 0,086 & 0,042 & $0,646^{* *}$ & 0,095 & 0,140 & - & - & - & - \\
\hline RP1 & 0,139 & 0,036 & $-0,004$ & 0,099 & $-0,124$ & 0,103 & 0,006 & $-0,067$ & 0,008 & 0,139 & 0,150 & $-0,116$ & 0,051 & $0,189^{*}$ & - & - & - \\
\hline $\mathrm{RP} 2$ & 0,011 & 0,080 & 0,091 & 0,022 & $-0,117$ & 0,158 & 0,054 & 0,042 & $-0,035$ & 0,045 & 0,156 & $-0,136$ & 0,008 & 0,090 & $0,607^{* *}$ & - & - \\
\hline RP3 & $-0,113$ & 0,088 & 0,164 & 0,029 & $-0,059$ & $0,221^{*}$ & 0,009 & 0,030 & $-0,016$ & $-0,051$ & 0,097 & $-0,184^{*}$ & $-0,010$ & 0,049 & $0,382^{* *}$ & $0,698^{* *}$ & - \\
\hline UG1 & $-0,125$ & $-0,067$ & $-0,106$ & $-0,053$ & $-0,091$ & 0,113 & 0,073 & $-0,085$ & $-0,151$ & 0,076 & $-0,080$ & $-0,213^{*}$ & $-0,035$ & 0,005 & 0,064 & $-0,029$ & $-0,016$ \\
\hline UG2 & $-0,051$ & $-0,068$ & $-0,232^{*}$ & $-0,018$ & 0,062 & 0,064 & 0,060 & 0,095 & $-0,084$ & 0,083 & $-0,127$ & $-0,183^{*}$ & $-0,095$ & $-0,178$ & 0,143 & 0,044 & 0,027 \\
\hline UG3 & $-0,029$ & 0,086 & $-0,018$ & 0,044 & 0,044 & 0,006 & 0,033 & $-0,192^{*}$ & $-0,085$ & $-0,059$ & 0,057 & $-0,109$ & $-0,122$ & 0,132 & 0,157 & $-0,117$ & $-0,204^{*}$ \\
\hline UV1 & $-0,198^{*}$ & $-0,003$ & 0,010 & $-0,078$ & 0,028 & $0,733^{* *}$ & $0,333^{* *}$ & $-0,018$ & 0,054 & 0,079 & $-0,044$ & $-0,662^{* *}$ & $-0,237^{*}$ & $-0,057$ & 0,110 & 0,081 & 0,124 \\
\hline UV2 & $-0,079$ & 0,028 & $-0,129$ & $-0,021$ & 0,087 & $0,337^{* *}$ & $0,694^{* *}$ & $0,219^{*}$ & 0,014 & $0,185^{*}$ & $-0,119$ & $-0,312^{* *}$ & $-0,553^{* *}$ & $-0,243^{* *}$ & 0,103 & 0,063 & 0,015 \\
\hline UV3 & $-0,033$ & 0,093 & $-0,023$ & 0,016 & 0,033 & 0,065 & 0,170 & $0,428^{* *}$ & $-0,147$ & 0,023 & 0,039 & $-0,195^{*}$ & $-0,188^{*}$ & $-0,283^{* *}$ & 0,113 & $-0,051$ & $-0,157$ \\
\hline
\end{tabular}

(a) $\mathrm{PRG}=$ produtividade de grãos do feijão, NVP = número de vagens por planta, $\mathrm{NGV}=$ número de grãos por vagem, $\mathrm{NGP}=$ número de grãos por planta, $\mathrm{MCG}=$ massa de cem grãos, $\mathrm{DS}=$ densidade do solo, $\mathrm{DP}=$ densidade da partícula, $\mathrm{PT}=$ porosidade total, $\mathrm{RP}=$ resistência à penetração; atributo precedido por \# identifica resíduo dos dados; ${ }^{(\mathbf{b})} \exp =\operatorname{exponencial,~esf~}=$ esférico e epp $=$ efeito pepita puro; modelo sucedido por número entre parêntesis, significando o número de pares no primeiro lag; ${ }^{(c)} \mathrm{SQR}=$ soma dos quadrados dos resíduos; ${ }^{(\mathrm{d})} \mathrm{ADE}=$ avaliador da dependência espacial. 
Já em relação a DS1, essa correlação com a PRG indicou função decrescente entre causa e efeito, ou seja, com a diminuição da DS1 ocorrerá um aumento da PRG, sendo o inverso verdadeiro. Desta forma, esse fato ficou de acordo com o verificado por Santos et al. (2006), que observaram a mesma tendência para a densidade do solo, quando correlacionada com a produtividade de grãos de milho, em um Latossolo Vermelho distroférrico. As correlações entre o número de grãos por vagem (NGV) e os atributos do solo (Tabela 2) apresentaram significância exclusivamente para o par NGV x UG2 $\left(\mathrm{r}=-0,232^{*}\right)$. As correlações entre os atributos DS x PT, estabelecidas nas mesmas camadas do solo (Tabela 2), foram todas negativas, de magnitudes altas, assim como significativas. Essa observação está correta, uma vez que a DS foi utilizada no cálculo da PT, conforme estabelecido pela Equação 2. A correlação DS1 x PT1 representou o maior valor do coeficiente de correlação $\left(r=-0,785^{* *}\right)$.

A relação inversa entre a DS x PT atestou que, com o aumento da densidade do solo, ocorrerá uma diminuição da porosidade total, o que concorda com o observado por Carvalho et al. (1999) e Secco et al. (2005). Já as correlações entre DP x PT, também estabelecidas nas mesmas camadas do solo (Tabela 2), foram todas diretas e significativas, com DP1 x PT1 $\left(r=0,227^{*}\right), \mathrm{DP} 2 \times \mathrm{PT} 2\left(\mathrm{r}=0,275^{* *}\right)$ e DP3 x PT3 $\left(r=0,646^{* *}\right)$ (Tabela 2$)$.

As principais equações de regressão linear simples entre os atributos pesquisados, no âmbito das correlações estabelecidas entre planta e solo, para o cultivo mínimo, estão apresentadas nas Figuras 1a, 1b e 1c. Portanto, os modelos foram exclusivamente apresentados para os pares de atributos que proporcionaram correlações significativas, assim como apresentaram coeficientes adjuntos significativos para as variáveis independentes.

No âmbito da correlação dos atributos da planta versus os do solo (Figura 1), houve regressões significativas da PRG, em função da DS1, PT1, UV1. Foi verificado que: a) a PRG apresentou uma variação exponencial indireta com a DS1 (Tabela 2, Figura 1a). Portanto, quando ocorrer o mínimo valor da DS1 $\left(0,921 \mathrm{~kg} \mathrm{dm}^{-3}\right)$, isso implicará valor máximo estimado da PRG igual a $2202 \mathrm{~kg} \mathrm{ha}^{-1}$. Assim, para o máximo da DS1 (1,574 $\left.\mathrm{kg} \mathrm{dm}^{-3}\right)$, o valor mínimo da PRG, de $1833 \mathrm{~kg} \mathrm{ha}^{-1}$, b) a PRG apresentou uma variação exponencial direta com a PT1 (Tabela 2, Figura 1b). Assim, quando ocorrer o máximo valor da PT1 $\left(0,544 \mathrm{~m}^{3} \mathrm{~m}^{-3}\right)$, isso implicará valor máximo da PRG, igual a $2153 \mathrm{~kg} \mathrm{ha}^{-1}$; c) a PRG apresentou uma variação potencial indireta com a UV1 (Tabela 2, Figura 1c). Portanto, quando ocorrer o mínimo valor da UV1 $\left(0,170 \mathrm{~m}^{3} \mathrm{~m}^{-3}\right)$ isso implicará máximo estimado da PRG, igual a $2217 \mathrm{~kg} \mathrm{ha}^{-1}$ (Figura 1).

Na Tabela 3, estão apresentados os parâmetros dos semivariogramas simples, ajustados para a produtividade do feijão, e de alguns atributos físicos do solo estudado.
Já nas Figuras 2 e 3, foram apresentados seus respectivos semivariogramas. Assim, ficou atestado que, com exceção da\#PRG, NVP, NGV, \#NGP, MCG, DS1, DP1, DP2, DP3, PT1, PT2, PT3, \#RP1, UG1, \#UV1, que apresentaram efeito pepita puro, todos os demais atributos apresentaram dependência espacial. No tocante ao desempenho dos semivariogramas, a relação decrescente deles, analisada pela grandeza do coeficiente de determinação espacial $\left(\mathrm{r}^{2}\right)$, foi a seguinte: 1) UV3 $(0,965), 2) \mathrm{RP} 2(0,964), 3) \mathrm{UG} 3(0,929)$, 4) UG2 (0,853), 5) DS2 (0,842), 6) RP3 (0,743), 7) \#DS3 $(0,678)$ e 8$)$ UV2 $(0,579)$. Assim, em relação aos dois primeiros (UV3 e RP2), que apresentaram elevados coeficientes de determinação espacial, observou-se o seguinte, conforme relatado a seguir:
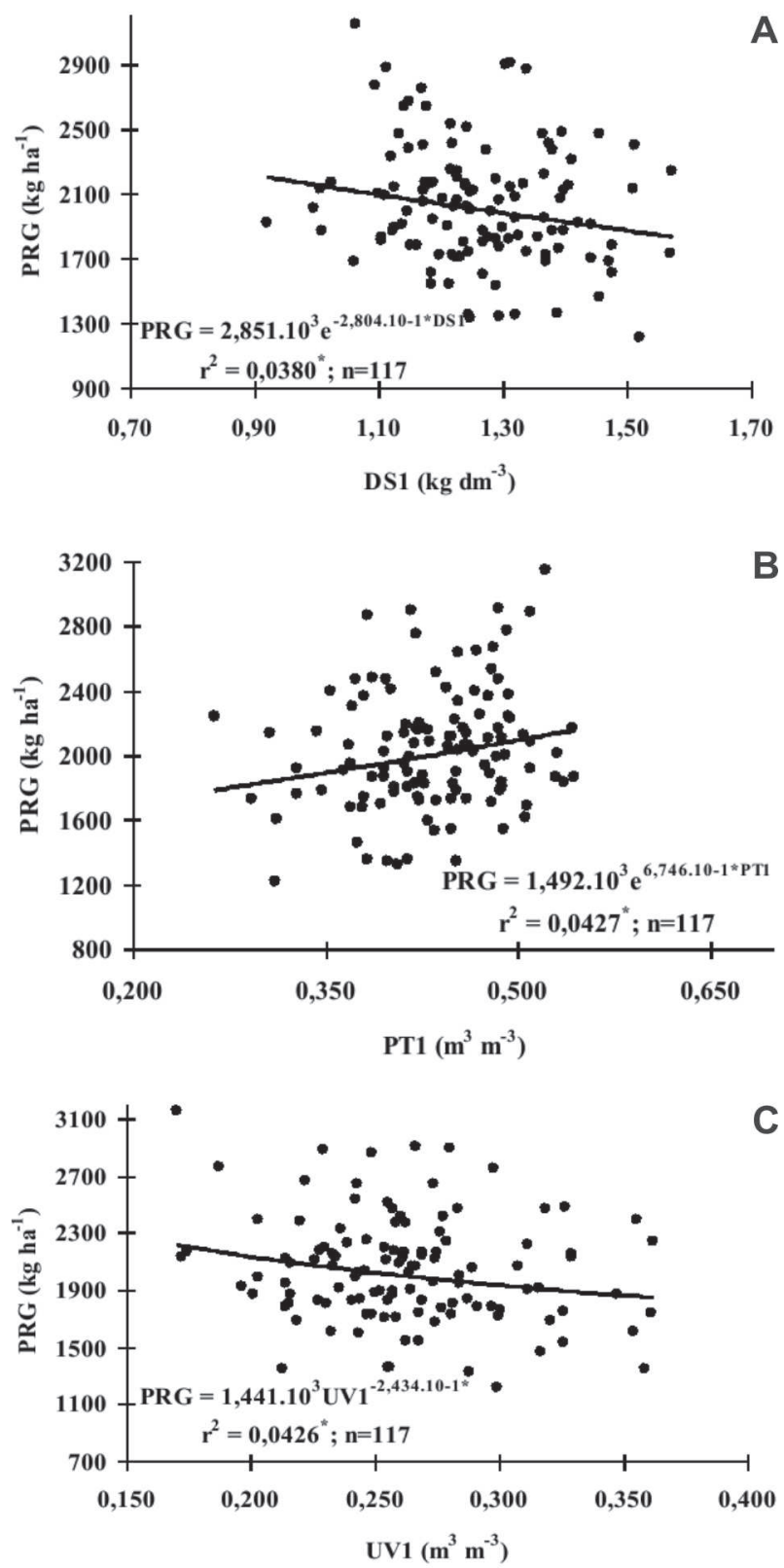

Figura 1. Equações de regressão entre atributos da cultura do feijão e de um Latossolo Vermelho distroférrico sob cultivo mínimo em Selvíria (MS).

Rev. Ceres, Viçosa, v. 60, n.6, p. 772-784, nov/dez, 2013 
Para o primeiro caso (UV3), seu valor de $\mathrm{r}^{2}(0,965)$, que indicou ser esse atributo o segundo de melhor ajuste semivariográfico, discordou daquele verificado por Martins (2006), que foi de 0,488 . Em relação ao ADE, o elevado valor $(89,2 \%)$ concordou com o de Martins et al. (2009), que foi de $85,8 \%$. Também o modelo exponencial ajustado para a UV3 assemelhou-se ao constatado por Martins et al. (2009). O alcance do UV3 deste trabalho $(7,2 \mathrm{~m})$ foi menor do que aquele do citado autor, de 22,8 $\mathrm{m}$ (Tabela 3 ).

No segundo caso (RP2), seu valor de $\mathrm{r}^{2}(0,964)$, que indicou ser esse atributo o terceiro de melhor ajuste semivariográfico, concordou com aquele verificado por Santos et al. (2005), que foi de 0,966. Em relação ao ADE, o forte valor verificado $(87,3 \%)$ discordou do de Santos et al. (2005), que foi moderado (73,5\%). O modelo esférico, ajustado para o RP2, ficou de acordo com o observado por Santos et al. (2005) e Carvalho et al. (2006), diferentemente do modelo exponencial obtido por Freddi et al. (2006). Também, o alcance do RP2 deste trabalho (7,7 m) foi menor do que todos aqueles dos citados autores, que variaram entre 20,2 e 67,1 m (Tabela 3).

Analisando-se a Tabela 3, constata-se que a relação decrescente dos alcances foi a seguinte: 1) UG3 (25,6 m), 2) RP3 (14,7 m), 3) UG2 (11,1 m), 4) DS2 (9,8 m), 5) RP2 e UV2 (7,7 m), 6) UV3 (7,2 m) e 7) \#DS3 (6,6 m). Portanto, nas condições desta pesquisa, assim como, visando a auxiliar pesquisas futuras, em que os mesmos atributos estejam envolvidos, sugere-se que os valores dos alcances a serem utilizados nos pacotes geoestatísticos que alimentarão os pacotes computacionais empregados na agricultura de precisão, no geral, não deverão ser menores do que $6,6 \mathrm{~m}$ (Tabela 3 ).

Tabela 3. Parâmetros dos semivariogramas simples ajustados para alguns atributos da cultura do feijão e de um Latossolo Vermelho distroférrico sob cultivo mínimo em Selvíria (MS)

\begin{tabular}{|c|c|c|c|c|c|c|c|c|}
\hline \multirow{3}{*}{ Atributo $^{(a)}$} & \multicolumn{8}{|c|}{ Parâmetros } \\
\hline & \multirow[t]{2}{*}{ Modelo $^{(b)}$} & \multirow{2}{*}{$\begin{array}{l}\text { Efeito Pepita } \\
\qquad\left(\mathrm{C}_{0}\right)\end{array}$} & \multirow{2}{*}{$\begin{array}{c}\text { Patamar } \\
\left(\mathrm{C}_{0}+\mathrm{C}\right)\end{array}$} & \multirow{2}{*}{$\begin{array}{l}\text { Alcance } \\
(\mathbf{m})\left(\mathbf{A}_{0}\right)\end{array}$} & \multirow[t]{2}{*}{$\mathbf{r}^{2}$} & \multirow[t]{2}{*}{$\mathbf{S Q R} \mathbf{R}^{(\mathrm{c})}$} & \multicolumn{2}{|c|}{$\begin{array}{c}\text { Avaliador da } \\
\text { dependência espacial }\end{array}$} \\
\hline & & & & & & & $\mathbf{A D E}^{(\mathbf{d})}$ & Classe \\
\hline \multicolumn{9}{|c|}{$\gamma(\mathbf{h})$ simples dos atributos da planta } \\
\hline \#PRG $\left(\mathrm{kg} \mathrm{ha}^{-1}\right)$ & epp & $1,163.10^{5}$ & $1,163.10^{5}$ & - & - & - & - & - \\
\hline NVP & epp & 4,382 & 4,382 & - & - & - & - & - \\
\hline NGV & epp & $5,410.10^{-1}$ & $5,410.10^{-1}$ & - & - & - & - & - \\
\hline \#NGP & epp & $1,041 \cdot 10^{2}$ & $1,041 \cdot 10^{2}$ & - & - & - & - & - \\
\hline MCG & epp & 1,121 & 1,121 & - & - & - & - & - \\
\hline \multicolumn{9}{|c|}{$\gamma(\mathrm{h})$ simples dos atributos físicos do solo } \\
\hline $\mathrm{DS} 1\left(\mathrm{~kg} \mathrm{dm}^{-3}\right)$ & epp & $1,552 \cdot 10^{-1}$ & $1,552.10^{-1}$ & - & - & - & - & - \\
\hline $\operatorname{DS} 2\left(\mathrm{~kg} \mathrm{dm}^{-3}\right)$ & $\exp (44)$ & $7,600.10^{-4}$ & $8,250.10^{-3}$ & 9,8 & 0,842 & $3,540.10^{-6}$ & 90,8 & forte \\
\hline \#DS3 $\left(\mathrm{kg} \mathrm{dm}^{-3}\right)$ & $\operatorname{esf}(50)$ & $1,998.10^{-3}$ & $4,736.10^{-3}$ & 6,6 & 0,678 & $1,448.10^{-6}$ & 57,8 & moderada \\
\hline $\mathrm{DP} 1\left(\mathrm{~kg} \mathrm{dm}^{-3}\right)$ & epp & $1,270.10^{-1}$ & $1,270.10^{-1}$ & - & - & - & - & - \\
\hline $\mathrm{DP} 2\left(\mathrm{~kg} \mathrm{dm}^{-3}\right)$ & epp & $1,004 \cdot 10^{-1}$ & $1,004 \cdot 10^{-1}$ & - & - & - & - & - \\
\hline DP3 $\left(\mathrm{kg} \mathrm{dm}^{-3}\right)$ & epp & $1,182.10^{-1}$ & $1,182.10^{-1}$ & - & - & - & - & - \\
\hline PT1 $\left(\mathrm{m}^{3} \mathrm{~m}^{-3}\right)$ & epp & $3,164 \cdot 10^{-2}$ & $3,164.10^{-2}$ & - & - & - & - & - \\
\hline PT2 $\left(\mathrm{m}^{3} \mathrm{~m}^{-3}\right)$ & epp & $2,779.10^{-2}$ & $2,779.10^{-2}$ & - & - & - & - & - \\
\hline PT3 $\left(\mathrm{m}^{3} \mathrm{~m}^{-3}\right)$ & epp & $1,958 \cdot 10^{-2}$ & $1,958 \cdot 10^{-2}$ & - & - & - & - & - \\
\hline \#RP1 (MPa) & epp & $3,114 \cdot 10^{-1}$ & $3,114 \cdot 10^{-1}$ & - & - & - & - & - \\
\hline RP2 (MPa) & esf (44) & $1,440.10^{-1}$ & 1,132 & 7,7 & 0,964 & $1,510.10^{-2}$ & 87,3 & forte \\
\hline RP3 (MPa) & $\exp (51)$ & $3,297.10^{-1}$ & $7,200.10^{-1}$ & 14,7 & 0,743 & $1,920.10^{-2}$ & 54,2 & moderada \\
\hline UG1 $\left(\mathrm{kg} \mathrm{kg}^{-1}\right)$ & epp & $5,180.10^{-3}$ & $5,180.10^{-3}$ & - & - & - & - & - \\
\hline UG2 $\left(\mathrm{kg} \mathrm{kg}^{-1}\right)$ & $\exp (48)$ & $4,900 \cdot 10^{-5}$ & $3,970.10^{-4}$ & 11,1 & 0,853 & $7,045 \cdot 10^{-9}$ & 87,1 & forte \\
\hline UG3 $\left(\mathrm{kg} \mathrm{kg}^{-1}\right)$ & $\exp (102)$ & $1,720.10^{-4}$ & $3,550.10^{-4}$ & 25,6 & 0,929 & $1,364 \cdot 10^{-9}$ & 51,4 & moderada \\
\hline \#UV1 $\left(\mathrm{m}^{3} \mathrm{~m}^{-3}\right)$ & epp & $1,195 \cdot 10^{-3}$ & $1,195 \cdot 10^{-3}$ & - & - & - & - & - \\
\hline $\operatorname{UV} 2\left(\mathrm{~m}^{3} \mathrm{~m}^{-3}\right)$ & $\exp (58)$ & $9,240.10^{-4}$ & $1,536.10^{-3}$ & 7,7 & 0,579 & $8,306 \cdot 10^{-8}$ & 39,8 & moderada \\
\hline $\operatorname{UV} 3\left(\mathrm{~m}^{3} \mathrm{~m}^{-3}\right)$ & $\exp (49)$ & $8,000 \cdot 10^{-5}$ & $7,410.10^{-4}$ & 7,2 & 0,965 & $3,934 \cdot 10^{-9}$ & 89,2 & forte \\
\hline
\end{tabular}

(a) $\mathrm{PRG}=$ produtividade de grãos do feijão, NVP = número de vagens por planta, NGV = número de grãos por vagem, NGP = número de grãos por planta, $\mathrm{MCG}=$ massa de cem grãos, $\mathrm{DS}=$ densidade do solo, $\mathrm{DP}=$ densidade da partícula, $\mathrm{PT}=$ porosidade total, $\mathrm{RP}=$ resistência à penetração; atributo precedido por \# identifica resíduo dos dados; ${ }^{(\mathbf{b})}$ exp = exponencial, esf = esférico e epp = efeito pepita puro; modelo sucedido por número entre parêntesis, significando o número de pares no primeiro lag; (c) $\mathrm{SQR}=$ soma dos quadrados dos resíduos; (d) ADE = avaliador da dependência espacial. 
Nas Figuras 2 e 3, estão apresentados os mapas de krigagem dos atributos do solo estudado. Em relação aos mapas apresentados, serão comentados aqueles de elevada semelhança espacial para efeito prático de manejo do solo. Dessa forma, foi observada a referida

DS2
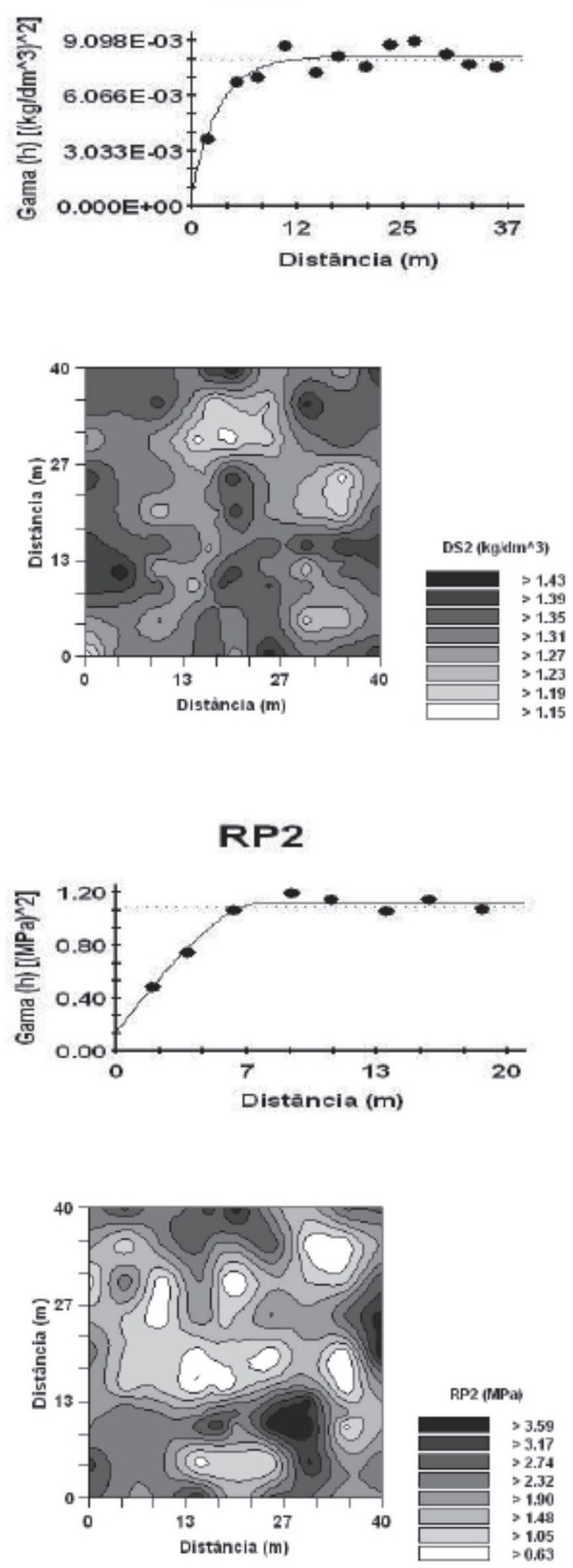

semelhança entre o mapa da densidade do solo (DS2) e o mapa da resistência à penetração (RP2). Assim, ainda na Figura 2, são observados os mapas de krigagem da densidade do solo (DS2) e da resistência à penetração (RP2) que apresentaram os menores valores $(1,15-1,27$
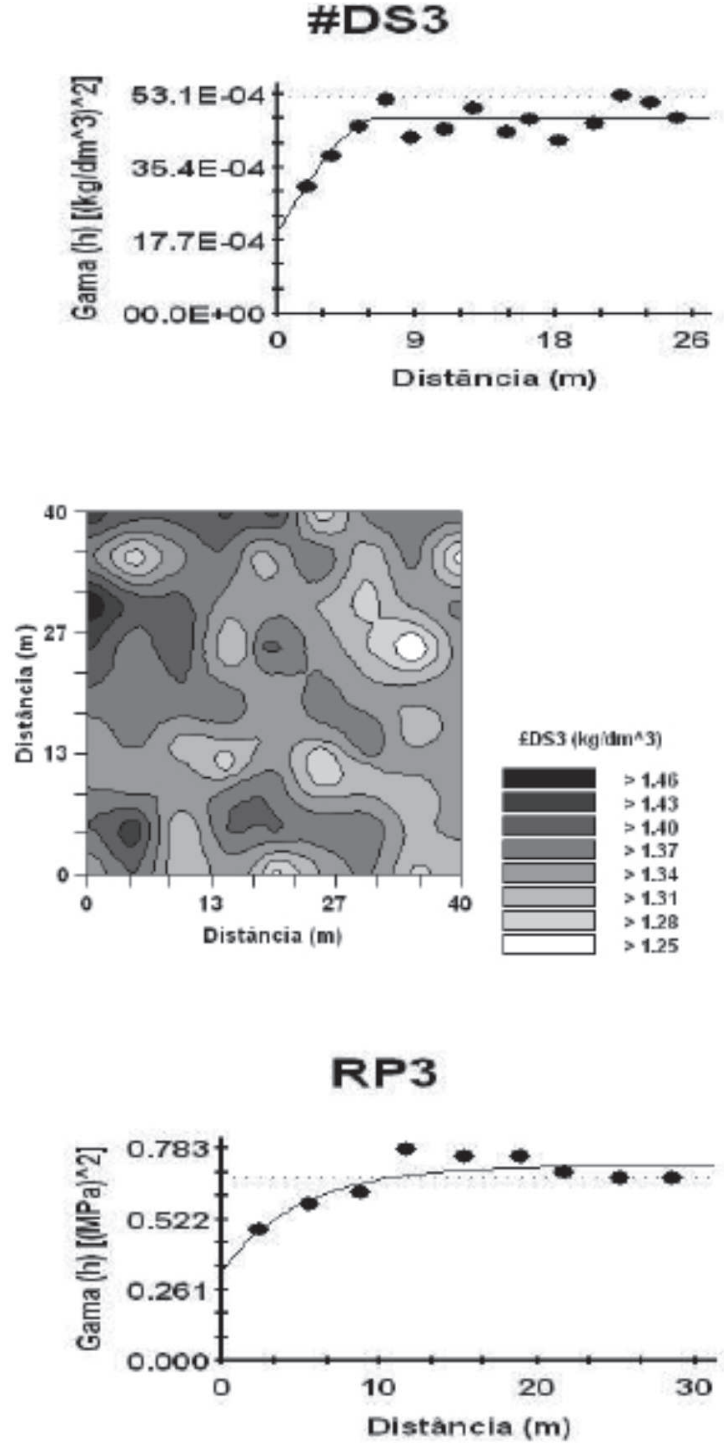

Figura 2. Componentes geoestatísticos dos atributos físicos (DS e RP) de um Latossolo Vermelho distroférrico sob cultivo de feijão em Selvíria (MS). 
$\mathrm{kg} \mathrm{dm}{ }^{-3}$ e 0,63-1,90 MPa), concentrados, em sua maioria, na região norte do mapa. Por outro lado, nas demais regiões, densidade e resistência variaram entre 1,31$1,43 \mathrm{~kg} \mathrm{dm}^{-3}$ e 2,32-3,59 MPa, respectivamente. Esse mesmo comportamento foi observado por Martins et

UG2
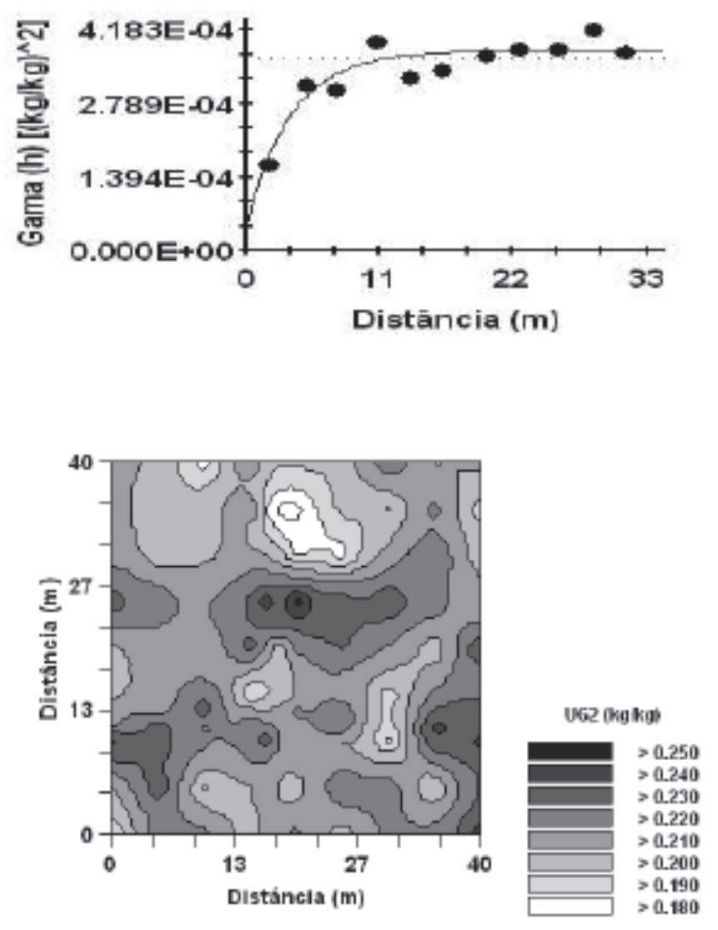

UV2
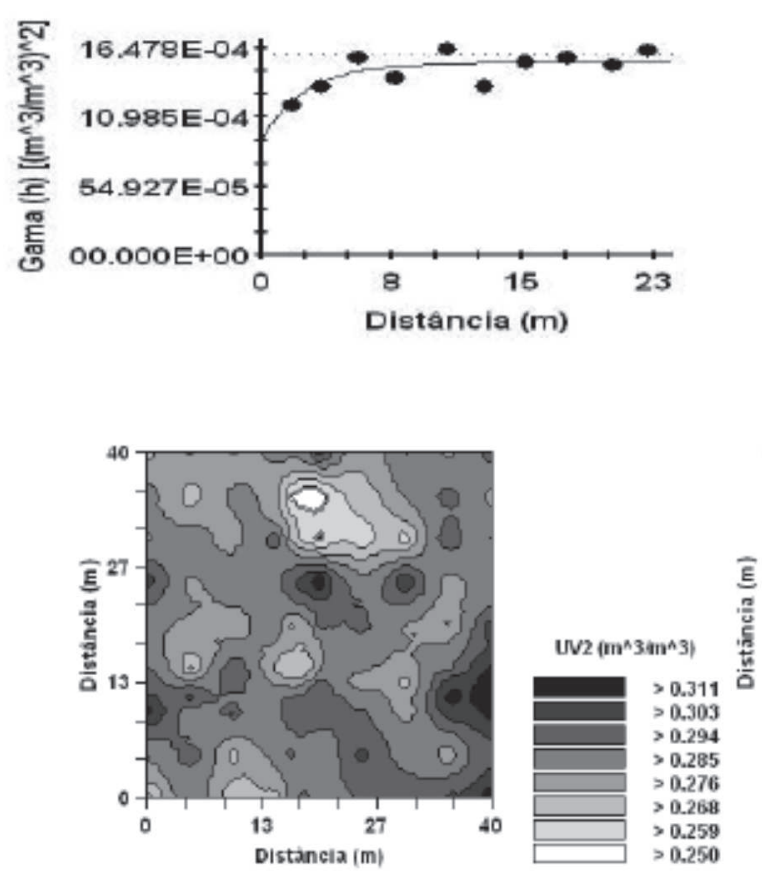

al. (2009), que encontraram elevada similaridade dos mapas entre a densidade do solo e a resistência à penetração de um Latossolo Vermelho distroférrico, sob plantio direto, nas profundidades $0-0,10$ e 0,10-0,20 m (Figuras 2 e 3 ).

\section{UG3}
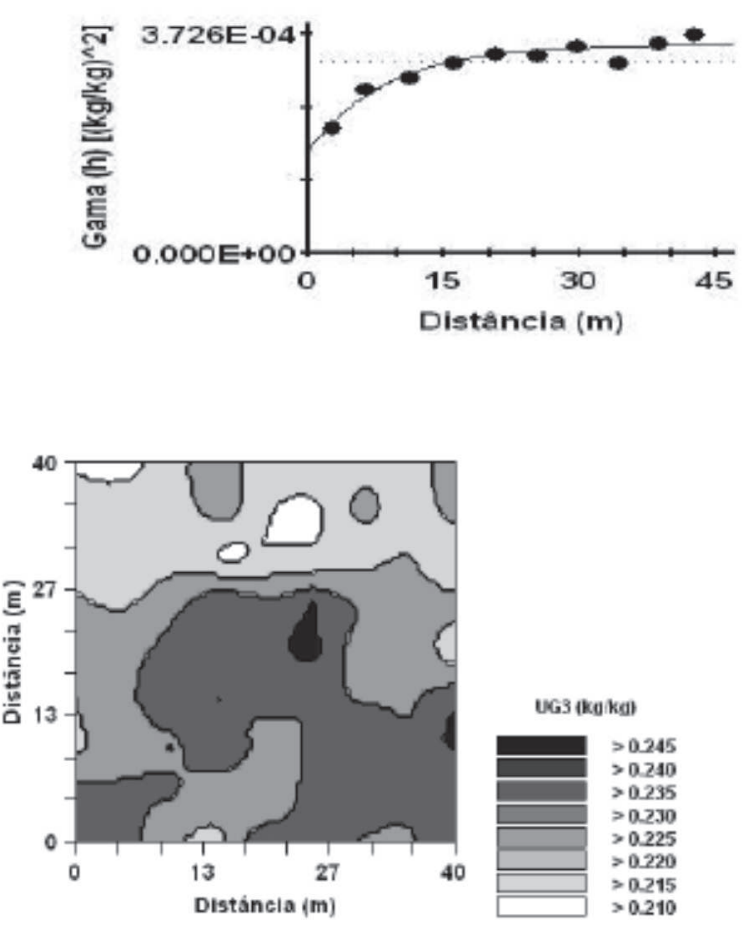

UV3
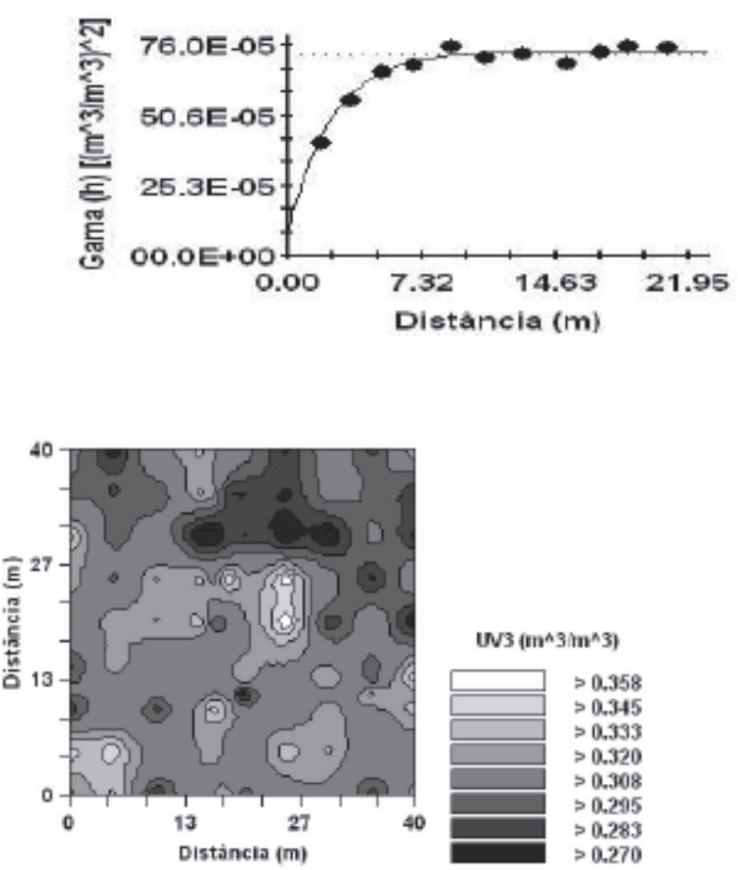

Figura 3. Componentes geoestatísticos dos atributos físicos (UG e UV) de um Latossolo Vermelho distroférrico sob cultivo de feijão em Selvíria (MS). 


\section{CONCLUSÕES}

Mesmo nas condições de adequado nível tecnológico de manejo da cultura, a produtividade média de grãos de feijão não atingiu seus limites potenciais. Isso, provavelmente, ocorreu porque o estado de compactação presente no solo, sob o sistema cultivo mínimo, pode ter provocado a redução de 33,3 \% dessa produtividade.

Os valores médios da densidade do solo, de 1,26-1,35 $\mathrm{kg} \mathrm{dm}^{-3}$, considerados prejudiciais ao desenvolvimento da cultura, provocaram queda substancial da produtividade de grãos de feijão.

Do ponto de vista linear, a produtividade de grãos de feijão foi explicada por um modelo potencial inverso significativo, dado em função da densidade do solo e da umidade volumétrica da camada superficial do solo.

\section{REFERÊNCIAS}

Bonini AK, Secco D, Santos RF, Reinert DJ \& Reichert JM (2011) Atributos físico-hídricos e produtividade de trigo em um Latossolo sob estados de compactação. Ciência Rural, 41:1543-1548.

Camargo AMMP, Caser DV \& Francisco VLFS (2001). Previsões e estimativas das safras agrícolas no estado de São Paulo. Informações Econômicas, 31:101-117.

Campos MCC, Soares MDR, Oliveira IA, Santos LAC \& Aquino RE (2013) Spatial variability of physical attributes in Alfisol under agroforestry, Humaitá region, Amazonas state, Brazil. Revista de Ciências Agrárias, 56:149-159.

Carvalho EJM, Figueiredo MS \& Costa LM (1999) Comportamento físico hídrico de um Podzóllico Vermelho-amarelo câmbico fase terraço sob diferentes sistemas de manejo. Pesquisa Agropecuária Brasileira, 34:257-265.

Carvalho MP, Soratto RP \& Freddi OS (2002) Variabilidade espacial de atributos físicos de um Latossolo Vermelho distrófico sob preparo convencional em Selvíria, Estado de Mato Grosso do Sul. Acta Scientiarum Agronomy, 24:1353-1361.

Carvalho MP, Takeda EY \& Freddi OS (2003) Variabilidade espacial de atributos de um solo sob videira em Vitória Brasil (SP). Revista Brasileira de Ciência do Solo, 27:695-703.

Carvalho GJ, Carvalho MP, Freddi OS \& Martins MV (2006) Correlação da produtividade do feijão com a resistência à penetração do solo sob plantio direto. Revista Brasileira de Engenharia Agrícola e Ambiental, 10:765-771.

Companhia Nacional de Abastecimento - Conab (2011) Safra 2010/2011: Quarto Levantamento - Janeiro/2011. Safra 2011/ 2012: Primeiro Levantamento - Outubro/2011. Acessado em: <http://www.conab.gov.br/conabweb>. Disponível em: <http:// www.conab.gov.br/conabweb>.

Dalchiavon FC, Carvalho MP, Freddi OS, Andreotti M \& Montanari R (2001) Variabilidade espacial da produtividade do feijoeiro correlacionada com atributos químicos de um Latossolo Vermelho distroférrico sob sistema de semeadura direta. Bragantia, 70:908-916.

Demattê JLI (1980) Levantamento detalhado de solos do "Campus Experimental de Ilha Solteira". Piracicaba, Escola Superior de Agricultura "Luiz de Queiroz". 44p.

Empresa Brasileira de Pesquisa Agropecuária - Embrapa (1997) Manual de métodos de análise de solos. $2^{\mathrm{a}}$ ed. Rio de Janeiro, Embrapa/CNPS. 212p.
Empresa Brasileira de Pesquisa Agropecuária - Embrapa (2006) Sistema brasileiro de classificação de solos. $2^{\mathrm{a}}$ ed. Rio de Janeiro, Embrapa. 306p.

Fahl JI, Camargo MBP, Pizzinatto MA, Betti JA, Melo AMT, De Maria IC \& Furlani AMC (1998) Instruções agrícolas para as principais culturas econômicas. $6^{\mathrm{a}}$ ed. Campinas, Instituto Agronômico. 393p. (Boletim técnico, 200).

Freddi OS, Carvalho MP, Centurion JF \& Barbosa GF (2005) Variabilidade espacial da produtividade do feijão em um Latossolo Vermelho distroférrico sob preparo convencional e plantio direto. Acta Scientiarum Agronomy, 27:61-67.

Freddi OS, Carvalho MP, Carvalho GJ \& Veronese Junior V (2006) Produtividade do milho relacionada com a resistência mecânica à penetração do solo sob preparo convencional. Engenharia Agrícola, 26:113-121.

Gabriel Filho A, Pessoa ACS, Strohhaecker L \& Helmich JJ (2000) Preparo convencional e cultivo mínimo do solo na cultura de mandioca em condições de adubação verde com ervilhaca e aveia preta. Ciência Rural, 30:953-957.

$\mathrm{GS}^{+}$: Geostatistics for environmental sciences (2004) $7^{\mathrm{a}}$ ed. Plainwell, Gamma Desing Software. 159p.

Kiehl EJ (1979) Manual de edafologia: relações solo-planta. São Paulo, Agronômica Ceres. 264p.

Libardi PL (2005) Dinâmica da água no solo. São Paulo, EDUSP. $335 \mathrm{p}$.

Martins AC (2006) Métodos de estimação da função semivariância aplicados a dados simulados e reais de produtividade da soja e de atributos físicos de um Latossolo. Dissertação de Mestrado. Universidade Estadual do Oeste do Paraná, Cascavel. 140p.

Martins MV, Carvalho MP, Andreotti M \& Montanari R (2009) Correlação linear e espacial entre a produtividade do feijoeiro e atributos físicos de um Latossolo Vermelho distroférrico de Selvíria, Estado de Mato Grosso do Sul. Acta Scientiarum Agronomy, 31:147-154.

Megda MM, Carvalho MP, Vieira MX, Andreotti M \& Pereira EC (2008) Correlação linear e espacial entre a produtividade de feijão e a porosidade de um Latossolo Vermelho de Selvíria (MS). Revista Brasileira de Ciência do Solo, 32:781-788.

Montanari R, Carvalho MP, Andreotti M, Dalchiavon FC, Lovera LH \& Honorato MAO (2010) Aspectos da produtividade do feijão correlacionados com atributo físicos do solo sob elevado nível tecnológico de manejo. Revista Brasileira de Ciência do Solo, 34:1811-1822.

Pimentel-Gomes FP \& Garcia CH (2002) Estatística aplicada a experimentos agronômicos e florestais. Piracicaba, FEALQ. 309 p.

Pompeu AS (1987) Melhoramento do feijoeiro (Phaseolus vulgaris L.). In: Bulisani EA (Ed.) Feijão fatores de produção e qualidade. Campinas, Fundação Cargill. p.01-28.

Roque MW, Matsura EE, Souza ZM, Bizari DR \& Souza AL (2008) Correlação linear e espacial entre a resistência do solo ao penetrômetro e a produtividade do feijoeiro irrigado. Revista Brasileira de Ciência do Solo, 32:1827-1835.

Roque AAO, Souza ZM, Araújo FS \& Silva GRV (2011) Atributos físicos do solo e intervalo hídrico ótimo de um Latossolo Vermelho distrófico sob tráfego controlado. Ciência Rural, 41:15361542 .

Santos ML, Carvalho MP, Rapassi RMA, Muraishi CT, Maller A \& Matos FA (2006) Correlação linear e espacial entre produtividade de milho (Zea mays - L.) e atributos físicos de um Latossolo Vermelho distroférrico sob plantio direto do Cerrado Brasileiro. Acta Scientiarum Agronomy, 28:313-321. 
Santos PA, Carvalho MP, Freddi OS, Kitamura AE, Freitag EE \& Vanzela LS (2005) Correlação linear e espacial entre o rendimento de grãos do feijoeiro e a resistência mecânica a penetração em um Latossolo Vermelho distrófico. Revista Brasileira de Ciência do Solo, 28:287-295.

SAS - Estatistical Analysis System Institute (1999) SAS/STAT Procedure guide for personal computers. $5^{\mathrm{a}}$ ed. Cary, Estatistical Analysis System Institute. 334p.

Secco D, Reinert DJ \& Reichert JM (2005) Atributos físicos e produtividade de culturas em um Latossolo Vermelho argiloso sob diferentes sistemas de manejo. Revista Brasileira de Ciência do Solo, 29:407-414.
Souza ZM, Marques Júnior J, Pereira GT \& Bento MJC (2004) Variabilidade espacial de atributos físicos de um Latossolo Vermelho sob cultivo de cana-de-açúcar. Revista Brasileira de Engenharia Agrícola e Ambiental, 8:51-58.

Souza ZM, Campos MCC, Cavalcante ÍHL, Marques Júnior J, Cesarin LG \& Souza SR (2006) Dependência espacial da resistência do solo à penetração e do teor de água do solo sob cultivo contínuo de cana-de-açúcar. Ciência Rural, 36:128-134.

Stolf R (1991) Teoria e teste experimental de fórmulas de transformação dos dados de penetrômetro de impacto em resistência do solo. Revista Brasileira de Ciência do Solo, 15:229-35. 